\title{
T1 and T2 mapping detect myocardial edema after repeated 200J electrical cardioversion
}

\author{
Dominik P Guensch ${ }^{1,2^{*}}$, Janelle Yu', Kady Fischer ${ }^{1}$, Gobinath Nadeshalingam', Matthias G Friedrich ${ }^{1}$ \\ From 17th Annual SCMR Scientific Sessions \\ New Orleans, LA, USA. 16-19 January 2014
}

\section{Background}

Electrical defibrillation and cardioversion are important and sometimes life-saving interventions. However, it remains controversial whether the intervention itself can significantly damage the heart. Myocardial edema is an early feature of myocardial injury that can be visualized by T2-weighted sequences. Newer approaches utilize T2 as well as T1 mapping techniques. We used T1 and T2 mapping to detect edema as a marker for defibrillation injury.

\section{Methods}

Using a 3T clinical MRI system, we assessed 10 anesthetized pigs at baseline and hourly for 5 hours after 5 consecutive synchronized transthoracic shocks of 200J and acquired images for T1 maps (MOLLI, modified looklocker inversion recovery) and T2 maps in three short-axis planes; basal, mid and apical. Six pigs undergoing the same protocol yet without shocks served as controls. After euthanasia and explantation of the hearts, tissue samples were obtained from regions of interest (ROI) defined by positive CMR results. Hematoxylin and eosin (HE) stains of these samples were then assessed for intercellular and interstitial edema using randomly sampled planimetry.

\section{Results}

In all 10 pigs undergoing shocks, we observed myocardial injury, which was located in the anterior and inferior wall $(\mathrm{n}=8)$, septal and inferior segments $(\mathrm{n}=1)$ or septal and lateral segments $(\mathrm{n}=1)$. In T1 and T2 maps, myocardial edema was predominantly observed in the basal slices. T2 was significantly increased from baseline at the first hour and at hours $3-5$ by up to $4.2 \pm 0.9 \%(\mathrm{p}<0.05$, Figure 2$)$ on a whole heart analysis, while $\mathrm{T} 2$ dropped in the remote myocardium (max. $-2.6 \pm 1.2 \%$, n.s.) and in the control pigs (max. $-6.1 \pm 0.7 \%, p=0.02$ ). On a slice by slice analysis the maximal increase was $11.3 \pm 3.9 \%$ in the basal slice $(\mathrm{p}<0.05)$. T1 was increased in affected ROI at 3 and $4 \mathrm{~h}$ post shock $(3.8 \pm 0.4 \%$ and $5.0 \pm 0.3 \% \mathrm{p}<0.01)$. Histology data showed that myocardial cell area increased by $185.65 \%(\mathrm{p}=0.016)$ while interstitial area was expanded 953.06\% compared to healthy control myocardium ( $\mathrm{p}=$ 0.016 ) in regions being deemed injured by either $\mathrm{T} 1$ or $\mathrm{T} 2$ maps. Both, cell area and interstitial space were correlated to $\mathrm{T} 1(\mathrm{~ms})$ in ROI $(\mathrm{r}=0.6 / \mathrm{p}=0.04$ and $\mathrm{r}=0.44 / \mathrm{p}=$ 0.037 , respectively).

\section{Conclusions}

Repeated cardioversion/defibrillation consistently leads to cellular and interstitial myocardial and skeletal edema, which can be visualized by T1 mapping and T 2 mapping.

\section{Funding}

Funding is provided by the Montreal Heart Institute Foundation and the Canadian Foundation for Innovation. 


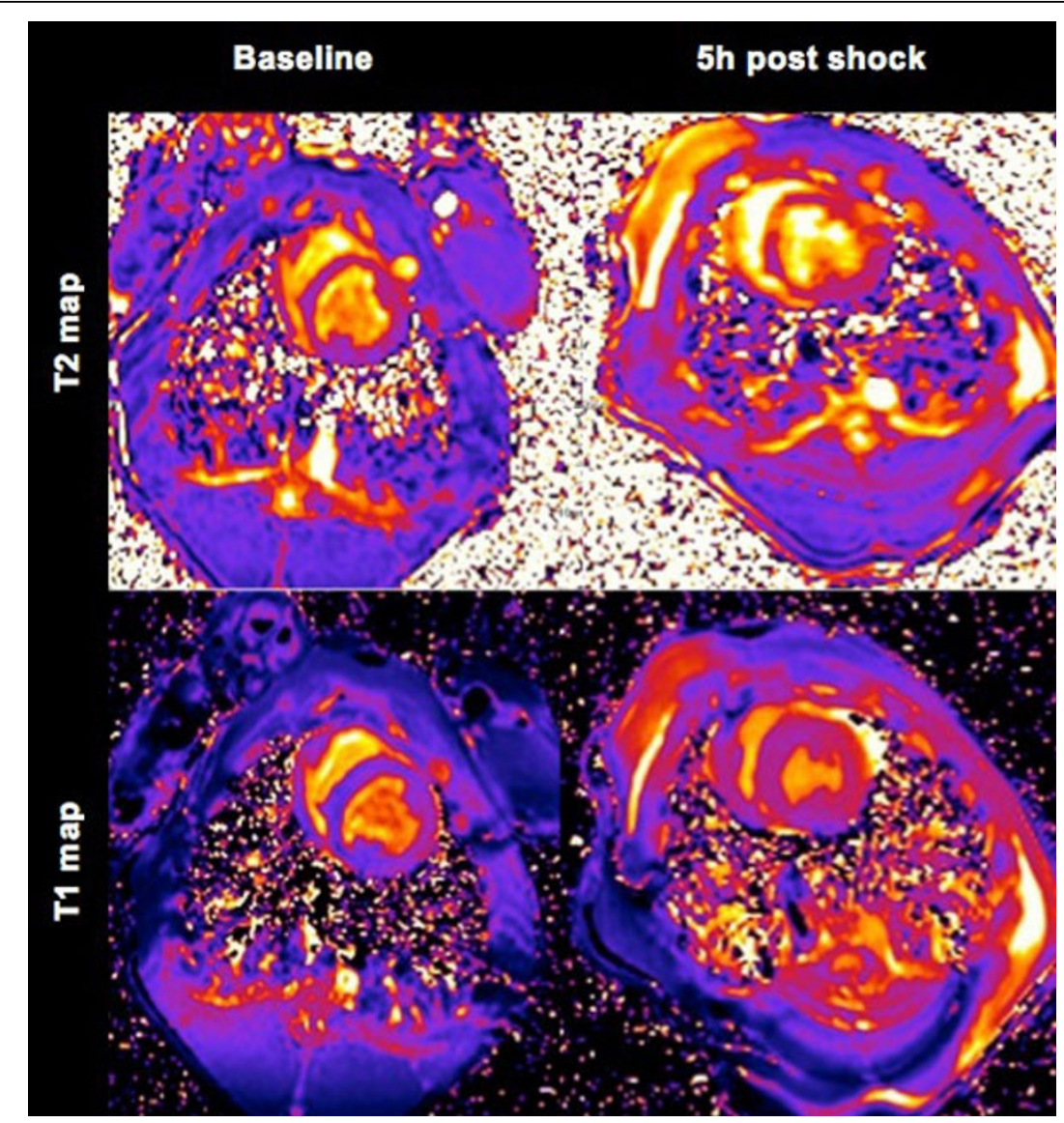

Figure $1 \mathrm{~T} 1$ and T2 maps at baseline before (left) and $5 \mathrm{~h}$ after cardioversion (right) of $5 \times 200 \mathrm{~J}$, The T2 maps show a T2 increase in the right pectoral muscle, the anterior RV and the septum. The T1 maps exhibit the location of the defibrillation pads and global T1

increase in the LV.

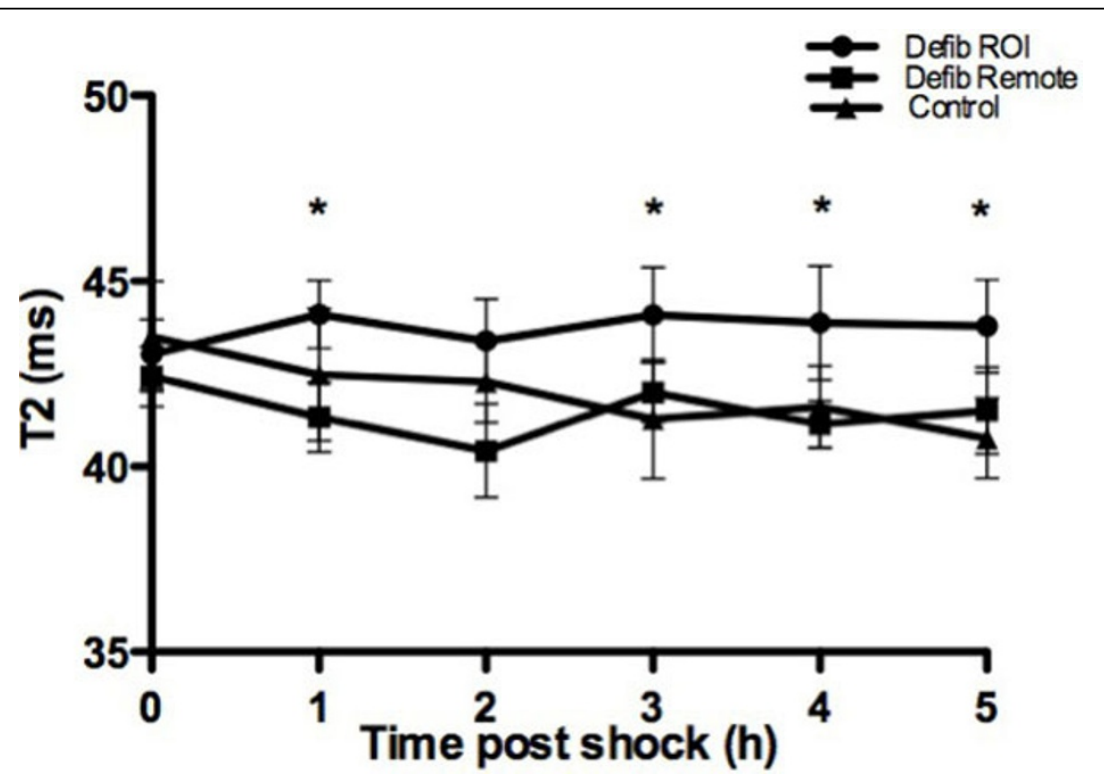

Figure 2 Mean \pm SEM change of T2 in regions of interest (ROI), remote myocardium of defibrillated pigs and in the myocardium of control pigs in the whole heart based analysis ( ${ }^{*} p<0.05$ ROI vs. Remote). 


\section{Authors' details}

${ }^{1}$ Philippa \&Marvin Carsley CMR Centre, Montreal Heart Institute, Montreal,

Quebec, Canada. ${ }^{2}$ Anesthesiology and Pain Medicine, University Hospital

Bern, Bern, Switzerland.

Published: 16 January 2014

doi:10.1186/1532-429X-16-S1-P157

Cite this article as: Guensch et al:: T1 and T2 mapping detect

myocardial edema after repeated 200J electrical cardioversion. Journal

of Cardiovascular Magnetic Resonance 2014 16(Suppl 1):P157.

Submit your next manuscript to BioMed Central and take full advantage of:

- Convenient online submission

- Thorough peer review

- No space constraints or color figure charges

- Immediate publication on acceptance

- Inclusion in PubMed, CAS, Scopus and Google Scholar

- Research which is freely available for redistribution

Submit your manuscript at 